\title{
Analysis of Air Pollutant concentration change trend in Urumqi city under the condition of city closed in winter
}

\author{
Zhang Haizhen ${ }^{1,}$, Wei Jiang ${ }^{2 *}$, \\ ${ }^{1}$ College of Continuing Education, Chongqing Vocational Institute of Engineering, Chongqing 402260, China; \\ ${ }^{2}$ Tourism School of Xinjiang University of Finance and Economics, 830021, China
}

\begin{abstract}
During the epidemic period, Urumqi has been sealed off from the city's management, just as"suspended" state.From an environmental point of view, the reduction of energy consumption during the closure of the city can be considered as an energy control to study the resulting reduction of atmospheric pollutant concentration changes.In this paper, the monitoring data of air pollutant concentration in the same period of city closure and normal years are compared, and the results show that the air pollutant concentration has decreased in different degrees during the period of city closure. The largest decrease was$44.66 \%$ for $\mathrm{NO}_{2},-40.13 \%$ for $\mathrm{CO},-36.44 \%$ for $\mathrm{PM}_{2.5}$, and the smallest was- $2.06 \%$ for $\mathrm{SO}_{2}$.Multivariate analysis of variance showed that energy control had a significant effect on the concentration of pollutants during the city closure, for example $\mathrm{NO}_{2}$ ( $\mathrm{F}=128.96$, Sig.=0.000), PM10（F=29.58, Sig=0.000）,PM2.5 $(\mathrm{F}=13.98, \mathrm{Sig} .=0.000), \mathrm{CO}(\mathrm{F}=46.34 ; \mathrm{Sig} .=0.000)$. Through the analysis of the data, it can be concluded that the air quality of Urumqi in winter is poor and the concentration of pollutants is high. The energy control during the closing period played a positive role in pollutant emission reduction and effectively improved the quality of atmospheric environment.
\end{abstract}

\section{Introduction}

The formation and development of a city is a process in which all kinds of factors, such as human flow and material flow, gather together in a certain region, and it is also a dense area of human life and production. When the concentration of pollutants discharged into the atmosphere in the process of human life and production exceeds the threshold of the atmospheric environmental capacity in the region, the problem of atmospheric environmental pollution arises.This has become a common problem in many large and medium-sized cities, especially in developing countries with relatively backward economies. The status of air pollution is usually closely related to the city's geographical location, the city's development stage and the structure of energy consumption ${ }^{[1]}$.

Urumqi is the capital of Xinjiang,it is also the Center of the political, economic and Cultural of Xinjiang. In the course of urban development, it has also experienced serious atmospheric environmental problems, which are mainly related to the typical "valley-type" geographical position and energy structure ${ }^{[2]}$. From the point of view of pollution status, the concentration of air pollutants in the city presents a "U"-shaped change trend, that is, the concentration of pollutants in the heating period is much higher than that in the non-heating period, and the difference of pollutant content in different regions shows that there are some differences of pollution sources in different regions, the quality of surrounding environment is related to industrial production and transportation, while the urban area is mainly related to motor vehicle exhaust and social $\operatorname{life}^{[3]}$.How much does the motor vehicle exhaust and social life in the city center have to do with air pollution? This is a question that environmental researchers have been thinking about, but it seems to be an incalculable problem, and social management during an epidemic provides an opportunity to study it.

From January 29 to March 4,2020, the city of Urumqi was closed down due to the outbreak of the new crown disease. Other social production and living activities were "suspended" except those related to the national economy and the people's livelihood.This is an extremely disadvantageous state for economic and social development, but it also provides a rare opportunity for environmental research.In this paper, we compare the monitoring data of air pollutant concentration in the same period of epidemic time (energy control) and in the normal state, and discuss the air pollutant that the city life releases to the air environment.

\section{Data acquisition and processing}

In this paper, the daily average data of air pollutants in the same period in 2019 and 2020 from state-controlled environmental quality monitoring sites in Urumqi are selected as the analysis objects.Air Pollutants include $\left(\mathrm{PM}_{10}, \mathrm{PM}_{2.5}, \mathrm{SO}_{2}, \mathrm{NO}_{2}, \mathrm{CO}\right.$ and $\left.\mathrm{O}_{3}-8 \mathrm{~h}\right)$.For ease of

\footnotetext{
$\overline{{ }^{*} \text { Corresponding author: 16826657@qq.com }}$
} 
analysis, the areas covered by the monitoring points are divided into southern, central and northern urban areas (Figure 1). The samples were collected by Thermo Scientific1405 Particle Monitor. The data is the average value of 0-23 points per day. Using WPS and SPSS19.0 to analyze the data.

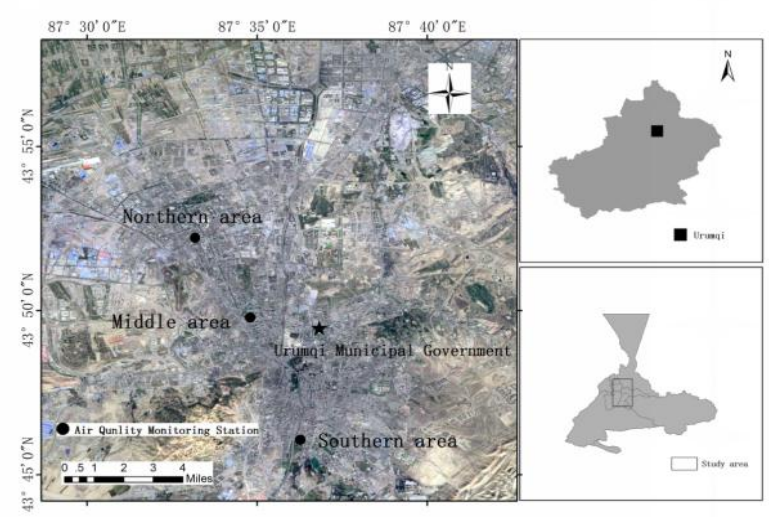

Figure 1 Monitoring point location area

\section{Results}

\subsection{Changes in environmental quality}

The statistics show that the environmental quality has improved significantly during the period of the city closure, with the I-class days appearing in different areas, moreover, the number of days of II environmental quality has also increased significantly, with $142 \%$ in the south area, $75 \%$ in the middle area, and $44.44 \%$ at the lowest in the north area. The days of III to VI levels of environmental quality showed a decreasing trend. Specific trends are shown in Table 1.

Table 1 Changes in air quality

\begin{tabular}{|c|c|c|c|c|c|c|c|c|c|}
\hline \multirow{2}{*}{\begin{tabular}{|c} 
Air \\
Quality \\
Rating
\end{tabular}} & \multicolumn{3}{|c|}{2019} & \multicolumn{3}{|c|}{2020} & \multicolumn{3}{|c|}{ Rate of change $(\%)$} \\
\hline & $\begin{array}{l}\text { Sout } \\
\text { hern }\end{array}$ & $\begin{array}{l}\text { Cen } \\
\text { tral }\end{array}$ & $\begin{array}{l}\text { Nort } \\
\text { hern }\end{array}$ & $\begin{array}{l}\text { Sout } \\
\text { hern }\end{array}$ & $\begin{array}{l}\text { Cen } \\
\text { tral }\end{array}$ & $\begin{array}{l}\text { Nort } \\
\text { hern }\end{array}$ & $\begin{array}{c}\text { Souther } \\
n\end{array}$ & Central & $\begin{array}{c}\text { North } \\
\text { ern }\end{array}$ \\
\hline I & & & & 3 & 5 & 2 & & & \\
\hline II & 7 & 8 & 9 & 17 & 14 & 13 & 142.86 & 75.00 & 44.44 \\
\hline III & 12 & 11 & 8 & 8 & 8 & 6 & -33.33 & -27.2 & -25.0 \\
\hline IV & 5 & 7 & 5 & 4 & 4 & 6 & -20.00 & -42.86 & 20.00 \\
\hline $\mathrm{V}$ & 10 & 7 & 10 & 3 & 3 & 6 & -70.00 & -57.14 & $\begin{array}{c}- \\
40.00 \\
\end{array}$ \\
\hline VI & 1 & 2 & 3 & & 1 & 2 & -100.00 & -50.00 & -33.3 \\
\hline
\end{tabular}

\subsection{Variation of pollutant concentrations in different regions}

During the city's closure, all motor vehicles (except special vehicles), restaurants and small industrial enterprises have been closed, resulting in a reduction in emissions of pollutants (Table2).

The change of pollutant concentration is very obvious, the concentration of $\mathrm{PM}_{10}$, in the particulate matter, showed a trend of low in the middle and high in the southern and north, with an average decrease of about $35 \%$, showing as the northern area $>$ southern $>$ middle area, that is $|-35.72 \% \quad|>|-34.40 \% \quad|>|-34.33 \% \quad|$. The spatial distribution of $\mathrm{PM}_{2.5}$ is the same as that of $\mathrm{PM}_{10}$, but the decreasing range shows the trend from south to north, which is southern $>$ middle area $>$ northern area, that is $|-36.44 \%|>|-28.48 \%|>|-16.38 \%|$; Among the gaseous pollutants, the concentration of NO2 decreased the most, and also showed a trend of decreasing from south to north, that is $|-44.66 \%|>|-37.90 \%|>|-33.69 \%|$;

The trend of $\mathrm{CO}$ change was basically the same as that of $\mathrm{NO}_{2}$, but the decrease of $\mathrm{CO}$ in the southern region was larger than that in the middle and north regions, that is $|-40.13 \%|>|-20.31 \%|>|-20.69 \%| . \mathrm{SO}_{2}$ decreases differently in different regions, but the overall magnitude is not large, ranging from- $15 \%$ to- $25 \%$. However, $\mathrm{O}_{3}$ $8 \mathrm{H}$ is different from other pollutants, but shows an increase trend, the increase range is relatively large, all in $50 \%$, from the spatial variation, the Southern $>$ the Northern $>$ the Central Zone, namely $81.64 \%>52.91 \%>$ $51.93 \%$.

Table2variation of pollutant concentration in different regions

Unit: $\mu \mathrm{g} / \mathrm{m}^{3}$

\begin{tabular}{|c|c|c|c|c|}
\hline Pollutants & Years & Southern & Central & Northern \\
\hline \multirow{3}{*}{$\mathrm{PM}_{10}$} & 2019 & 127.51 & 125.54 & 134.23 \\
\hline & 2020 & 83.65 & 82.44 & 86.29 \\
\hline & $(\%)$ & $-34.40 \%$ & $-34.33 \%$ & $-35.72 \%$ \\
\hline \multirow{3}{*}{$\mathrm{PM}_{2.5}$} & 2019 & 124.20 & 117.37 & 134.29 \\
\hline & 2020 & 78.94 & 83.94 & 112.29 \\
\hline & $(\%)$ & $-36.44 \%$ & $-28.48 \%$ & $-16.38 \%$ \\
\hline \multirow{3}{*}{$\mathrm{SO}_{2}$} & 2019 & 6.37 & 10.94 & 11.31 \\
\hline & 2020 & 4.83 & 8.26 & 9.57 \\
\hline & $(\%)$ & $-24.22 \%$ & $-24.54 \%$ & $-15.40 \%$ \\
\hline \multirow{3}{*}{$\mathrm{NO}_{2}$} & 2019 & 80.54 & 84.06 & 71.40 \\
\hline & 2020 & 44.57 & 52.20 & 47.34 \\
\hline & $(\%)$ & $-44.66 \%$ & $-37.90 \%$ & $-33.69 \%$ \\
\hline \multirow{3}{*}{$\mathrm{CO}$} & 2019 & 2.29 & 2.01 & 1.82 \\
\hline & 2020 & 1.37 & 1.60 & 1.45 \\
\hline & $(\%)$ & $-40.13 \%$ & $-20.31 \%$ & $-20.69 \%$ \\
\hline \multirow{3}{*}{$\mathrm{O}_{3}-8 \mathrm{H}$} & 2019 & 36.26 & 48.14 & 50.06 \\
\hline & 2020 & 65.86 & 73.14 & 76.54 \\
\hline & $(\%)$ & $81.64 \%$ & $51.93 \%$ & $52.91 \%$ \\
\hline
\end{tabular}

\subsection{Results of multivariate analysis of variance}

The statistical data show that the concentration of pollutants mainly showed a downward trend during the period of closure of the city, the environmental quality improved obviously, and the rate of decrease of the concentration of pollutants in different regions was different. Multiple factor difference test results, as shown in Table3, the most significant impact of energy control was $\mathrm{NO}_{2}(\mathrm{~F}=128.96$, Sig. $=0.000)$, followed by $\mathrm{CO}(\mathrm{F}=46.34$; Sig. $=0.000), \mathrm{PM}_{10}(\mathrm{~F}=29.58$, Sig. $=$ $0.000), \mathrm{PM}_{2.5}(\mathrm{~F}=13.98 .65$, Sig. $=0.000), \mathrm{SO} 2(\mathrm{~F}=$ 
48.38, Sig. $=0.000)$ and $\mathrm{O}_{3}-8 \mathrm{H}(\mathrm{F}=31.52$, Sig. $=0.000) \quad$ were the significant differences among the regions. Table 3 Multivariate analysis of variance

\begin{tabular}{|c|c|c|c|c|c|c|c|c|c|c|}
\hline \multicolumn{11}{|c|}{ Tests of Between-Subjects Effects } \\
\hline \multicolumn{6}{|c|}{ Dependent Variable: $\mathrm{PM}_{10}$} & \multicolumn{5}{|c|}{ Dependent Variable: $\mathrm{PM}_{2.5}$} \\
\hline Source & $\begin{array}{l}\text { Type III Sum } \\
\text { of Squares }\end{array}$ & df & $\begin{array}{l}\text { Mean } \\
\text { Square }\end{array}$ & $\mathrm{F}$ & Sig. & $\begin{array}{l}\text { Type III Sum } \\
\text { of Squares }\end{array}$ & $\mathrm{df}$ & Mean Square & $\mathrm{F}$ & Sig. \\
\hline Corrected Model & $115984.952 \mathrm{a}$ & 5 & $\begin{array}{l}23196.99 \\
2351510 .\end{array}$ & 6.03 & 0 & $86838.667 \mathrm{a}$ & 5 & 17367.733 & 4.10 & 0.001 \\
\hline Intercept & 2351510.876 & 1 & $\begin{array}{c}88 \\
113774.0\end{array}$ & 611.3 & 0 & 2472389.505 & 1 & 2472389.505 & 584.27 & 0 \\
\hline Energy control & 113774.019 & 1 & 2 & 29.577 & 0 & 59136.076 & 1 & 59136.076 & 13.98 & 0 \\
\hline areas & 2154.581 & 2 & 1077.29 & 0.28 & 0.756 & 22969.295 & 2 & 11484.648 & 2.71 & 0.069 \\
\hline \multicolumn{11}{|l|}{ Energy control } \\
\hline Error & 784734.171 & 204 & 3846.74 & & & 863239.829 & 204 & 4231.568 & & \\
\hline Total & 3252230 & 210 & & & & 3422468 & 210 & & & \\
\hline \multicolumn{6}{|c|}{ a.R Squared $=.122($ Adjusted R Squared $=.100)$} & $\begin{array}{c}950078.495 \\
\text { a.R Squared }=.0\end{array}$ & \multicolumn{3}{|c|}{ a.R Squared $=.091($ Adjusted R Squared $=.069)$} & \\
\hline \multicolumn{6}{|c|}{ Dependent Variable: $\mathrm{SO}_{2}$} & \multicolumn{5}{|c|}{ Dependent Variable: $\mathrm{NO}_{2}$} \\
\hline Corrected Model & $1158.195 \mathrm{a}$ & 5 & $\begin{array}{c}231.639 \\
15342.97\end{array}$ & 23.916 & 0 & $53282.895 \mathrm{a}$ & 5 & 10656.579 & 27.90 & 0 \\
\hline Intercept & 15342.976 & 1 & 6 & 1584.129 & 0 & 842840.076 & 1 & 842840.076 & 2206.98 & 0 \\
\hline Energy control & 2.1 & 1 & 2.1 & 0.217 & 0.642 & 49250.743 & 1 & 49250.743 & 128.96 & 0 \\
\hline areas & 937.152 & 2 & 468.576 & 48.379 & 0 & 2750.467 & 2 & 1375.233 & 3.60 & 0.029 \\
\hline \multicolumn{11}{|l|}{ Energy control } \\
\hline Error & 1975.829 & 204 & 9.685 & & & 77907.029 & 204 & 381.897 & & \\
\hline Total & 18477 & 210 & & & & 974030 & 210 & & & \\
\hline \multicolumn{5}{|c|}{ a.R Squared $=.37($ Adjusted R Squared $=.345)$} & & \multicolumn{5}{|c|}{ a.R Squared $=.406($ Adjusted R Squared $=.392)$} \\
\hline \multicolumn{6}{|c|}{ Dependent Variable:CO } & \multicolumn{5}{|c|}{ Dependent Variable: $\mathrm{O}_{3}-8 \mathrm{H}$} \\
\hline Corrected Model & $21.705 \mathrm{a}$ & 5 & 4.341 & 11.89 & 0 & $68923.498 \mathrm{a}$ & 5 & 13784.7 & 21.10 & 0 \\
\hline Intercept & 647.683 & 1 & 647.683 & 1774.19 & 0 & 642528.052 & 1 & 642528.052 & 983.62 & 0 \\
\hline Energy control & 16.915 & 1 & 16.915 & 46.34 & 0 & 15180.36 & 1 & 15180.36 & 23.24 & 0 \\
\hline areas & 1.574 & 2 & 0.787 & 2.16 & 0.118 & 41181.349 & 2 & 20590.674 & 31.52 & 0 \\
\hline $\begin{array}{c}\text { Energy control } \\
* \text { areas }\end{array}$ & 3.216 & 2 & 1.608 & 4.40 & 0.013 & 11300.933 & 2 & 5650.466 & 8.65 & 0 \\
\hline Error & 74.472 & 204 & 0.365 & & & 156121.187 & 239 & 653.227 & & \\
\hline Total & 743.86 & 210 & & & & 842344.05 & 245 & & & \\
\hline $\begin{array}{c}\text { Corrected Total } \\
\text { a. } \text { R Squared }=.22\end{array}$ & $\begin{array}{c}96.177 \\
6 \text { (Adjusted R }\end{array}$ & $\begin{array}{l}209 \\
\text { Square }\end{array}$ & $d=.207)$ & & & $\begin{array}{c}225044.685 \\
\text { a.R Squared }=.3\end{array}$ & $\begin{array}{l}244 \\
\text { (Adj }\end{array}$ & sted R Squared & $=.292)$ & \\
\hline
\end{tabular}

\section{Analysis and Discussion}

\subsection{The change of $\mathrm{PM}_{10}$ and $\mathrm{PM}_{2.5}$}

In winter, the air pollution in Urumqi is serious, mainly because the heating consumes a lot of fossil energy, at the same time, the motor vehicle hot-running time is long, the driving speed is slow, which causes a lot of tail gas emissions.Under normal conditions, the concentration of particulate pollutants appears to be high in the north and south area, and low in the middle area, which is directly related to the surrounding environment of the monitoring point. The North and south points are at both ends of the city, and on the one hand they are easily affected by the urban heat island effect, on the other hand, the main factors that affect the concentration of pollutants are the exposed ground surface in the suburbs and the dust produced by vehicles entering the city $^{[4]}$.

During the period of the city closure, $\mathrm{PM}_{10}$ decreased considerably. From the point of view of the extent of the decrease, namely the north $>$ the south $>$ the central, mainly after the closure of the city, the most important change was the total suspension of motor vehicles (except working vehicles and special vehicles) , therefore, the dust generated by motor vehicle operation 
has been contained and reduced to the lowest point, and the large drop in the northern area is due to its high concentration in the early stage, and the concentration of $\mathrm{PM}_{10}$ in the three monitoring sites after the closure of the city is very close, you could say it represents the background value of the city in winter.

The concentration of $\mathrm{PM}_{2.5}$ decreased obviously, but the average decrease was smaller than that of PM10. The main reason was that the ambient concentration of PM2.5 was almost the same as that of $\mathrm{PM}_{10}$ under normal conditions. Although the emission of motor vehicle exhaust was greatly reduced after the closure of the city, it might be affected by the inversion layer in winter, the ability of reducing pollutants is still limited, and the trend of $\mathrm{PM}_{2.5}$ is the same as that of $\mathrm{PM}_{10}$, which is consistent with the conclusion of the former study ${ }^{[5]}$.

The results of variance analysis also showed that city closure had significant effect on controlling $\mathrm{PM}_{10}$ and $\mathrm{PM}_{2.5}$, and the effect on $\mathrm{PM}_{10}$ was greater than that on $\mathrm{PM}_{2.5}$.

\subsection{The change of $\mathrm{SO}_{2}$ and $\mathrm{NO}_{2}$.}

The decrease rate of $\mathrm{SO}_{2}$ is obviously lower than that of $\mathrm{NO}_{2}$, which is mainly due to the adjustment of energy structure such as "coal to gas", the production of $\mathrm{SO}_{2}$ emissions is almost reduced to a minimum.

The concentration of $\mathrm{NO}_{2}$, the main pollutant of motor vehicle emission, has the biggest reduction. Under normal conditions, vehicle exhaust is the main pollution source of $\mathrm{NO}_{2}$ in urban area. After the closure of the city, motor vehicle exhaust emissions will almost reach zero, and the concentration of pollutants will also decrease, with the largest decrease in the southern area, mainly due to the complete shutdown of the passenger stations near the monitoring points, combined with a sharp decline in the number of vehicles on the nearby city's high-speed roads, the central district followed, with the northern district having the lowest rate of decline, also reaching$33.69 \%$. The results of variance analysis showed that the effect of urban closure on $\mathrm{NO}_{2}$ was the most significant, which indicated that the concentration of $\mathrm{NO}_{2}$ in Urumqi urban area in winter was about $40 \%$.

\subsection{The change of $\mathrm{CO}$ and $\mathrm{O}_{3}-8 \mathrm{H}$}

During the period of city closure, the $\mathrm{CO}$ reduction from south to North showed a decreasing trend. From the concentration point of view, the concentration in the south and the north of city was close to each other. But from the pollutant concentration point of view, the concentration value itself was low, and it was difficult to have a higher reduction. The analysis of variance showed that the effect of city closure on $\mathrm{CO}$ reduction was significant. $\mathrm{O}_{3}-8 \mathrm{H}$ is the main air pollutant, and it is also the only one whose concentration increased after the closure of the city, with an average increase of over $50 \%$.It can be concluded that the atmospheric environmental quality is improved, the atmospheric radiation is enhanced and the concentration of $\mathrm{O}_{3}-8 \mathrm{H}$ is increased due to the reduction of the overall pollutant emission.This is basically consistent with the conclusion that particles in the atmosphere during the heating period help to increase the diffraction and scattering of light.

\section{Conclusion}

The air pollution of Urumqi is serious in winter, and the concentration of pollutants is high.After the closure of the city, the concentration of pollutants showed a decreasing trend.

On the premise of constant consumption of conventional energy sources such as industrial production and heating, the concentration of pollutants caused by motor vehicles has dropped remarkably, it is shown that proper traffic diversion and control of the number of motor vehicles are effective means to improve the atmospheric environment quality.

The change range of different pollutants in the atmospheric environment is quite different from that of energy control and regional types. For example, the reduction of motor vehicles has the biggest effect on $\mathrm{NO}_{2}$ and the second effect on the concentration of atmospheric particulate matter, $\mathrm{SO}_{2}$ and $\mathrm{O}_{3}-8 \mathrm{H}$ require regional energy regulation.

City closed is an effective means to control the spread of the epidemic, which is extremely disadvantageous to economic and social development, but it is a rare opportunity to study the state of air pollution. However, due to the lack of previous experimental preparation and experience, there are some scientific problems, didn't take advantage of the opportunity to figure it out.

\section{References}

1. Noel de Nevers.Air Pollution Control Engineering(second edition ) [M]. McGraw-Hill. (2000).

2. Wei jiang, Wangguohua, Renquan etc al.Study on Quantitative Model of Concentration of Air Pollutants over Urumqi[J]. ARID ZONE RESEARCH,28,5(2011).

3. Chen xuegang, Wei Jiang, Ren quan,etc al. Effects of the urban expansion on the spatially varying trends of distribution in air pollutants concentration: a case study of Urumqi[J].ecology and environmental sciences,22,6(2013).

4. Juan Li, Guoshun Zhuang, Kan Huangect. Characteristics and sources of air-borne particulate in Urumqi,China, the upstream area of Asia dust [J]. Atmospheric Environment, 42 (2008).

5. Binggan Wei, Fengqing Jiang, Xuemei Li.Spatial distribution and contamination assessment of heavy metals in urban road dusts from Urumqi, NW China[J]. Microchemical Journal, (2009). 